\title{
Cathodic electrodeposition of CuSCN thin films
}

\author{
K. Okabe, ${ }^{1}$ Y. Selk, ${ }^{2}$ T. Oekermann ${ }^{2}$ and T. Yoshida ${ }^{*}$ \\ 1 Environmental and Renewable Energy Systems (ERES) Division, Graduate School of Engineering, \\ Gifu University, Yanagido 1-1 Gifu 501-1193, Japan \\ Fax: +81-058 293 2593, *e-mail: yoshida@apchem.gifu-u.ac.jp \\ 2 Institute of Physical Chemistry and Electrochemistry, University of Hannover, \\ Callinstrasse 3-3A, 30167 Hannover, Germany
}

Cathodic electrodepositon of $\mathrm{CuSCN}$ thin films on F-doped $\mathrm{SnO}_{2}$ (FTO) substrates has been investigated in aqueous mixed solution of copper perchlorate and lithium thiocyanate. Cathodic current arose around $+0.5 \mathrm{~V}$ vs. $\mathrm{Ag} / \mathrm{AgCl}$ and reached a plateau below ca. $+0.3 \mathrm{~V}$ in the mixed solution. Levich analysis of the plateau current confirmed limitation of $\mathrm{CuSCN}$ deposition by mass transport. The current was proportional almost symmetrically to the concentrations of $\mathrm{Cu}^{2+}$ and $\mathrm{SCN}^{-}$, suggesting that transport of their complex was responsible. Absorption spectrum of the mixed solutions indeed revealed an appearance of a new peak only when both $\mathrm{Cu}^{2+}$ and $\mathrm{SCN}^{-}$were present. Job plot for this peak elucidated formation of 1 to 1 complex. As the concentration of this active species could be determined from the absorption spectra, Levich analyses at different temperatures made it possible to determine the frequency factor $\left(D_{0}\right)$ of and the activation energy $\left(E_{\mathrm{a}}\right)$ for the diffusion of $\left(\mathrm{Cu}^{2+}\right)\left(\mathrm{SCN}^{-}\right)$complex as $3.24 \times 10^{-2} \mathrm{~cm}^{2} \mathrm{~s}^{-1}$ and $20.1 \mathrm{~kJ} \mathrm{~mol}^{-1}$, respectively. Key words: CuSCN, p-type semiconductor, thin film, electrodeposition, mass transport

\section{INTRODUCTION}

Dye sensitized solar cells (DSC) are under intense investigations because of their potentials in low cost and high energy conversion efficiency. Generally, DSC employs porous anodes processed from nanoparticles of $\mathrm{TiO}_{2}[1]$ and $\mathrm{ZnO}[2-5]$. The dye sensitized electrodes are in contact with electrolyte solutions containing $\mathrm{I}^{-} / \mathbf{I}_{3}{ }^{-}$ redox couple. The use of electrolyte solution is seen as a drawback of DSCs to make them unstable for a long term operation.

Ultimate solution to overcome the above mentioned problem is to substitute the electrolyte solution with solid hole conductors. Several wide band gap p-type compound semiconductors such as $\mathrm{CuI}$ [6-8], $\mathrm{CuAlO}_{2}$ [9], $\mathrm{NiO}[10]$ and $\mathrm{CuSCN}$ [11] have been proposed as suitable materials for this purpose. Among them, $\mathrm{CuSCN}$ is one of the most promising material because of its high chemical stability, carrier mobility and possibilities in filling pores by solution methods such as dip-coating [12], chemical bath deposition [13] and electrodeposition [14,15].

Electrodeposition is an industrially widely used method for coatings for its advantages such as (i) environmentally low load, (ii) rigid control of film thickness, uniformity and deposition rate and (iii) possibility of deposition on substrates with complex shape [16]. CuSCN can be cathodically electrodeposited from solutions containing $\mathrm{Cu}^{2+}$ and $\mathrm{SCN}^{-}[15,16]$. However, its deposition mechanism is not fully understood, unlike the established methods to electrodeposit metallic thin films.

In this paper, we have studied mechanism of electrodeposition of $\mathrm{CuSCN}$ from aqueous mixed solution of $\mathrm{Cu}\left(\mathrm{ClO}_{4}\right)_{2}$ and $\mathrm{LiSCN}$. It is very important to understand the mechanism of $\mathrm{CuSCN}$ deposition, especially its limiting factors to elucidate the conditions needed for filling the nano-sized pores. Electrochemical analysis under controlled mass transport employing rotating disk electrode (RDE) revealed that the formation of $\mathrm{CuSCN}$ was limited by transport of a complex between $\mathrm{Cu}^{2+}$ and $\mathrm{SCN}^{-}$under typical deposition conditions. Diffusion constants of the active species have been determined from Levich analysis of the limiting current.

\section{EXPELIMENTAL}

Fluorine doped $\mathrm{SnO}_{2}$ (FTO) coated glass $(10 \Omega / \square$, Asahi Glass) sheets cut into $2.5 \mathrm{~cm}$ square were cleaned ultrasonically in acetone, 2-propanol, soap solution, and water. They were activated in $45 \% \mathrm{HNO}_{3}$ for $2 \mathrm{~min}$ and finally rinsed with distilled water prior to the electrochemical experiments

Aqueous solutions containing $\mathrm{Cu}\left(\mathrm{ClO}_{4}\right)_{2}$ and $\mathrm{LiSCN}$ whose concentrations varied as $1.25,2.5,5.0$ and 7.5 $\mathrm{mM}$ were prepared using Milli-Q pure water (18.2 M $\Omega$ ). $\mathrm{LiClO}_{4}$ was further added to these solutions as a supporting electrolyte at $0.1 \mathrm{M}$.

A three-electrode single compartment cell was used equipped with an FTO glass as working, a platinum wire as counter, and an $\mathrm{Ag} / \mathrm{AgCl}$ as reference electrodes. The FTO grass was attached to a Radiometer Analytical EDI101 through an attachment to be used as an RDE. Potential control and current monitoring were achieved by a Hokuto Dennko HSV-100 potentiostat. The cell was placed in a thermostat bath to control the temperature in the range of 5 to $45^{\circ} \mathrm{C}$.

Absorption spectra of the sample solutions were measured on a HITACHI U-3500 spectrophotometer for various $\mathrm{Cu}^{2+}: \mathrm{SCN}^{-}$ratios and plotted absorbance at the maximum absorption of the complex against $\mathrm{Cu}^{2+}$ ion mole fraction (Job plot) to determine the composition of the complex.

\section{RESULTS AND DISCUSSION}


3.1 Redox reactions of $\mathrm{Cu}^{2+}, \mathrm{SCN}^{-}$and their mixture

Redox reactions of chemical species relevant to the formation of CuSCN were examined by means of cyclic voltammetry (Fig. 1). No appreciable current was observed in a solution containing only LiSCN in the potential range between +1.0 and $-0.5 \mathrm{~V}$ (data not shown) indicating that $\mathrm{SCN}^{-}$ion itself is electrochemically inactive. For a solution containing only $\mathrm{Cu}^{2+}$ (a), an abrupt increase of cathodic current is seen at around $-0.1 \mathrm{~V}$ that reaches a plateau in the more negative potential range (zone $I$ as indicated in the figure). It arises from electrodeposition of metallic $\mathrm{Cu}$.

$$
\mathrm{Cu}^{2+}+2 \mathrm{e}^{-} \rightarrow \mathrm{Cu}
$$

On reversal of the potential scan, an anodic peak is observed in zone II, corresponding to anodic stripping of the electrode due to oxidation of $\mathrm{Cu}$

$$
\mathrm{Cu} \rightarrow \mathrm{Cu}^{2+}+2 \mathrm{e}^{-}
$$

When both $\mathrm{Cu}^{2+}$ and $\mathrm{SCN}^{-}$are present in the solution (b), cathodic current appears at around $+0.5 \mathrm{~V}$, much more positive potential than it does in the solution only with $\mathrm{Cu}^{2+}$, and creates a plateau down to ca. $0 \mathrm{~V}$ (zone III). CuSCN is electrodeposited in this potential range, for which the overall reaction can be written as,

$$
\mathrm{Cu}^{2+}+\mathrm{SCN}^{-}+\mathrm{e}^{-} \rightarrow \mathrm{CuSCN}
$$

This reaction is reversible as anodic peak appears at around $+0.7 \mathrm{~V}$ (zone IV) which corresponds to oxidative decomposition of $\mathrm{CuSCN}$.

$$
\mathrm{CuSCN} \rightarrow \mathrm{Cu}^{2+}+\mathrm{SCN}^{-}+\mathrm{e}^{-}
$$

When the electrode potential is scanned down to $-1.0 \mathrm{~V}$ in the mixed solution (c), cathodic current further increases in zone I. Correspondingly, several anodic peaks appear in zone II, together with enlarged anodic peak in zone IV. In the potential range where reaction (1) is thermodynamically permitted, mixture of $\mathrm{Cu}$ and CuSCN is obtained. The anodic peaks in zone II should reflect oxidation of $\mathrm{Cu}$ and some other intermediate species.

From these analyses, it has become evident that underpotential deposition (UPD) of $\mathrm{Cu}^{2+}$ in presence of $\mathrm{SCN}^{-}$leading to a formation of $\mathrm{CuSCN}$ takes place in zone III and that is the range to obtain singly CuSCN thin film which is of our interest.

\subsection{Levich analysis}

Hydrodynamic electrochemical analysis has been performed for the plateau current in zone III of Fig. 1. When the current is limited by mass transport, the current varies proportionally to the square root of the rotation speed according to the Levich equation,

$$
I_{\mathrm{d}}=0.62 n F A C_{\mathrm{bulk}} D^{2 / 3} v^{-1 / 6} \omega^{1 / 2}
$$

where $n$ is the number of electrons, $F$ is the Faraday constant $\left(96,485 \mathrm{C} \mathrm{mol}^{-1}\right), A$ is the electrode area $(0.196$ $\left.\mathrm{cm}^{2}\right), C_{\text {bulk }}$ is the bulk concentration of active species $\left.(\mathrm{mol} \mathrm{cm})^{-3}\right), D$ is the diffusion coefficient $\left(\mathrm{cm}^{2} \mathrm{~s}^{-1}\right), \nu$ is the kinetic viscosity of solvent $\left(8.9 \times 10^{-3} \mathrm{~cm}^{2} \mathrm{~s}^{-1}\right.$ for water at $25^{\circ} \mathrm{C}$ ) and $\omega$ is the angular speed of RDE ( $\mathrm{rad}$ $\mathrm{s}^{-1}$ ). The analysis was carried out for mixed solutions in which concentration of $\mathrm{Cu}^{2+}$ or $\mathrm{SCN}^{-}$was fixed to 10 $\mathrm{mM}$ while varying the other between 0 and $10 \mathrm{mM}$. The current varied proportionally to the concentration of the minority species and it was almost symmetrical to $\mathrm{Cu}^{2+}$ and $\mathrm{SCN}^{-}$. An example of a set of $I-V$ curves are shown in Fig. 2(a) in which the concentrations of $\mathrm{Cu}^{2+}$ and $\mathrm{SCN}^{-}$are reversed. Levich plots of these $I-V$ curves fall into the same straight line going through the origin (Fig.2 (b)). This behavior implies that transport of $1: 1$ complex of $\mathrm{Cu}^{2+}$ and $\mathrm{SCN}^{-}$is the limiting process.

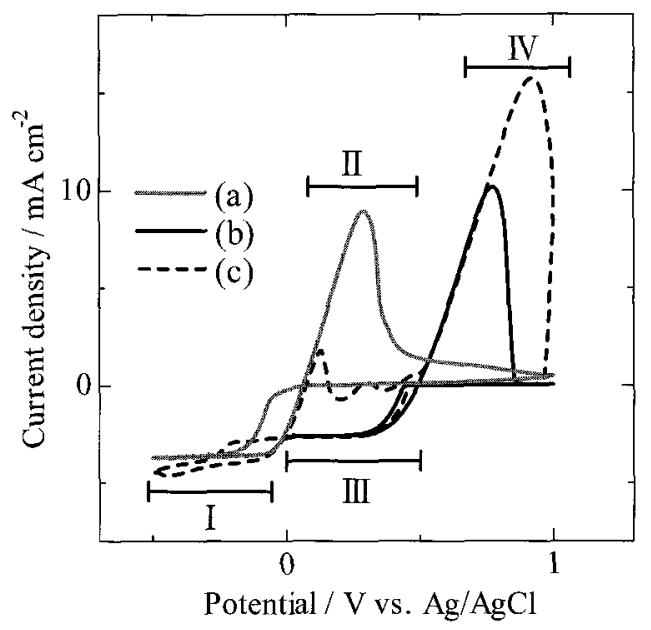

Fig.1 Cyclic voltammograms measured at an FTO coated glass RDE $(500 \mathrm{rpm})$ in aqueous solutions $\left(25^{\circ} \mathrm{C}\right)$ containing (a) $10 \mathrm{mM} \mathrm{Cu}\left(\mathrm{ClO}_{4}\right)_{2}$ and (b)(c) $10 \mathrm{mM}$ $\mathrm{Cu}\left(\mathrm{ClO}_{4}\right)_{2}$ and $5 \mathrm{mM} \mathrm{LiSCN}$. $\mathrm{LiClO}_{4}$ was added at 0.1 $M$ as supporting electrolyte in all solutions. The potential was scanned from the rest potential down to $-0.5 \mathrm{~V}(0 \mathrm{~V}$ for $(\mathrm{b}))$ and reversed to the positive end of $1.0 \mathrm{~V}$.

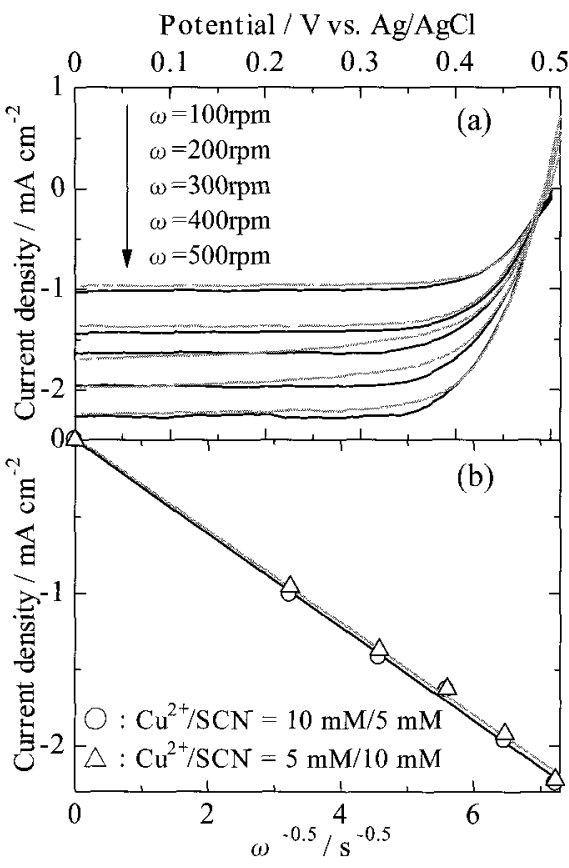

Fig.2 (a) $I-V$ curves measured at an FTO glass RDE for different rotation speeds between 100 and $500 \mathrm{rpm}$ in aqueous solutions $\left(25^{\circ} \mathrm{C}\right)$ containing $10 \mathrm{mM} \mathrm{Cu}\left(\mathrm{ClO}_{4}\right)_{2}$ $+5.0 \mathrm{mM} \mathrm{LiSCN}+0.1 \mathrm{M} \mathrm{LiClO}_{4}(-)$ and $5.0 \mathrm{mM}$ $\mathrm{Cu}\left(\mathrm{ClO}_{4}\right)_{2}+10 \mathrm{mM} \mathrm{LiSCN}+0.1 \mathrm{M} \mathrm{LiClO}_{4}(-)$. (b) Levich plots drawn from the plateau currents in (a). 3.3 Formation of complex between $\mathrm{Cu}^{2+}$ and $\mathrm{SCN}^{-}$ $\mathrm{SCN}^{-}$ion is known to coordinate to various metal ions [17]. In fact, the characteristic blue color of $\mathrm{Cu}\left(\mathrm{ClO}_{4}\right)_{2}$ 
solution turns into green when LiSCN is added. We have therefore traced formation of the complex by measuring absorption spectra of the mixed solutions.

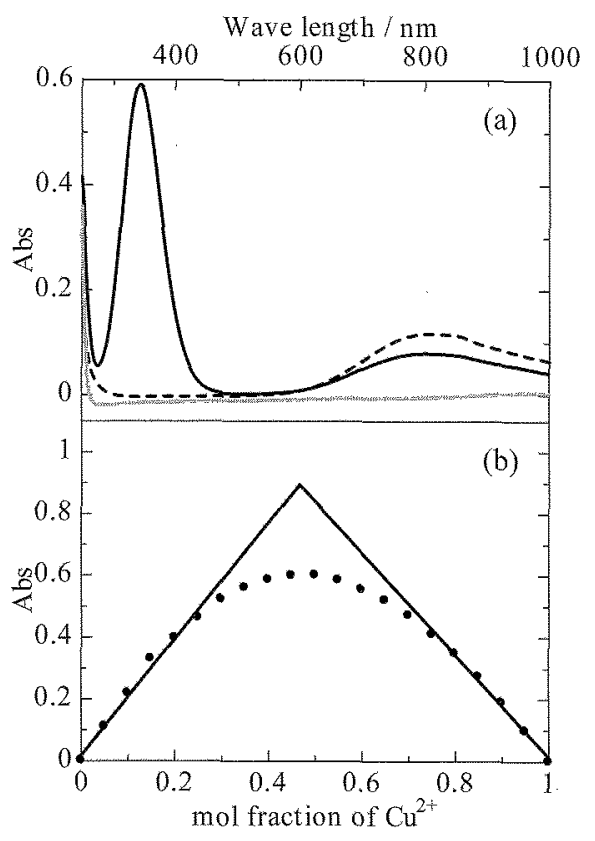

Fig.3 (a) Absorption spectra of aqueous solutions containing $10 \mathrm{mM} \mathrm{LiSCN}(-\infty), 10 \mathrm{mM} \mathrm{Cu}\left(\mathrm{ClO}_{4}\right)_{2}$ (-- ) and $10 \mathrm{mM} \mathrm{LiSCN}+10 \mathrm{mM} \mathrm{Cu}\left(\mathrm{ClO}_{4}\right)_{2}(-)$. (b) Job's plot drawn for the absorbance at $343 \mathrm{~nm}$ of aqueous solutions in which total concentration of $\mathrm{Cu}^{2+}+$ $\mathrm{SCN}^{-}$was fixed to $20 \mathrm{mM}$ and their proportion varied.

While solution of LiSCN does not exhibit any intense absorption, that of $\mathrm{Cu}\left(\mathrm{ClO}_{4}\right)_{2}$ shows a broad peak at around $820 \mathrm{~nm}$ due to $d-d$ transition of $\mathrm{Cu}^{2+}$ ion (Fig. 3(a)). When $\mathrm{SCN}^{-}$is added to the latter, a sharp absorption peak appears at $343 \mathrm{~nm}$ which should reflect charge transfer $(\mathrm{CT})$ transition of the complex. We have therefore drawn Job's plot for the absorbance of this CT band to determine the composition of the complex (Fig. $3(b))$. Since the highest absorbance is reached when the mole fraction of $\mathrm{Cu}^{2+}$ is about 0.5 , formation of 1 to 1 complex as being the dominant species is concluded. Comparison of the maximum absorbance with the value at the crossing point of linear fits for both ends of Job's plot can tell approximate concentration of the complex. From such a comparison, molar extinction coefficient for the CT transition peak of the complex could be determined as $1.84 \times 10^{2}\left(\mathrm{~mol} \mathrm{dm} \mathrm{dm}^{-3}\right)$. One can thus determine the concentration of the active species by monitoring the intensity of the $\mathrm{CT}$ band.

\subsection{Determination of diffusion coefficient}

From the analyses described above, it has become evident that $1: 1$ complex between $\mathrm{Cu}^{2+}$ and $\mathrm{SCN}^{-}$ (hereafter noted as $\left.\left(\mathrm{Cu}^{2+}\right)\left(\mathrm{SCN}^{-}\right)\right)$is the electrochemically active species and its transport limits the electrodeposition of CuSCN. Eq. (3) should therefore be rewritten as,

$\left(\mathrm{Cu}^{2+}\right)\left(\mathrm{SCN}^{-}\right)+\mathrm{e}^{-} \rightarrow \mathrm{CuSCN}$

The slope of Levich plot reflects concentration of the complex as well as its diffusion coefficient. While small changes of temperature typically do not affect the stability of the complex, thus its concentration, diffusion is a thermally activated process and should exhibit a temperature dependence. Such relationships are nicely seen in the plots shown in Fig. 4. The slope changes proportionally to the concentration of the complex for a given temperature but it varies for different temperatures. From the slopes of the plots in Fig. 4, diffusion coefficient in each temperature can be determined. For example, a central value of $1.05 \times 10^{-5}\left(\mathrm{~cm} \mathrm{~s}^{-1}\right)$ was obtained at $25^{\circ} \mathrm{C}$.

Diffusion coefficient is dependent on the temperature according to the following relationship,

$$
D=D_{0} \exp \left(-E_{a} / R T\right)
$$

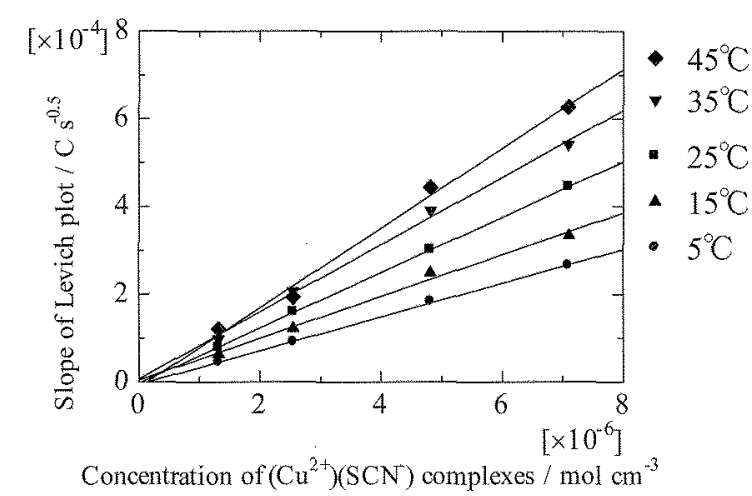

Fig.4 Slope of Levich plot measured for different temperatures plotted vs. concentration of $\left(\mathrm{Cu}^{2+}\right)\left(\mathrm{SCN}^{-}\right)$ complex.

where $D_{0}$ is the frequency factor of diffusion $\left(\mathrm{cm}^{2} \mathrm{~s}^{-1}\right)$, $E_{\text {a }}$ is the activation energy $\left(\mathrm{J} \mathrm{mol}^{-1}\right), R$ is the gas constant (8.3144 $\mathrm{J} \mathrm{mol}^{-1} \mathrm{~K}^{-1}$ ) and $T$ is the absolute temperature (K). Logarithm of eq. (6) expresses the commonly used relationship of Arrehenius plot.

$$
\ln D=-E_{\mathrm{a}} / R T+\ln D_{0}
$$

The Arrhenius plot of the diffusion coefficient and temperature yields a straight line as shown in Fig. 5 . Activation energy $\left(E_{\mathrm{a}}\right)$ of $20.1 \mathrm{~kJ} \mathrm{~mol}^{-1}$ was determined from the slope, while frequency factor $\left(D_{0}\right)$ of $3.24 \times$ $10^{-2} \mathrm{~cm}^{2} \mathrm{~s}^{-1}$ resulted from the intercept of extrapolation of the linear fit at the ordinate.

Having elucidated these constants for the transport of $\left(\mathrm{Cu}^{2+}\right)\left(\mathrm{SCN}^{-}\right)$complex and also knowing its molar absorption coefficient, one can predict limiting current under given parameters of electrolysis.

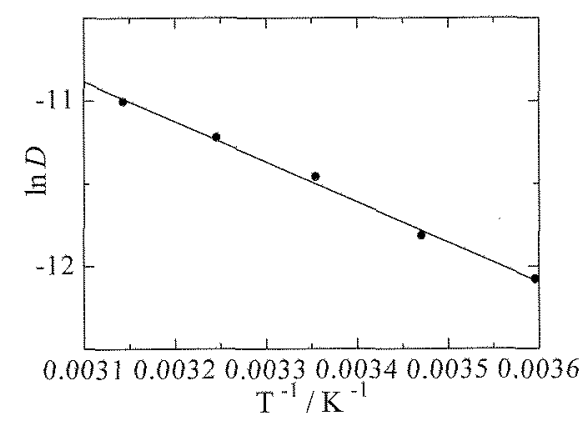

Fig.5 Arrhenius plot drawn from the relationship between diffusion coefficient and temperature. 
3.5 Morphology of electrodeposited CuSCN

An SEM image of a typical CuSCN thin film electrodeposited at $+0.2 \mathrm{~V}$, namely, under the transport limited regime is shown in Fig.6. The quantity of $\mathrm{Cu}^{2+}$ electrodeposited as CuSCN was determined by colorimetry by dissolving the film with a known area into a known volume of ammonia and employing sodium diethylthiocarbamate as indicator [18]. Its comparison to the consumed charge revealed Faradic efficiency of almost $100 \%$. The current limited by mass transport can therefore be directly translated into the rate of CUSCN deposition.

Contrary to the expectations for such a transport limited film growth, the deposited film is not compact consisting of rugged particles with large gaps in between them. X-ray diffraction (XRD) pattern of the film indicated formation of well crystallized CuSCN (data not shown). Faceted growth of crystalline CuSCN particles therefore indicates surface reorganization during the film growth. It is also noticed that particles grow on top of the others, indicating progressive nucleation of CuSCN crystallites. Understanding of the rate of surface reorganization relative to that of nucleation seems to be necessary to understand the evolution of the film morphology.

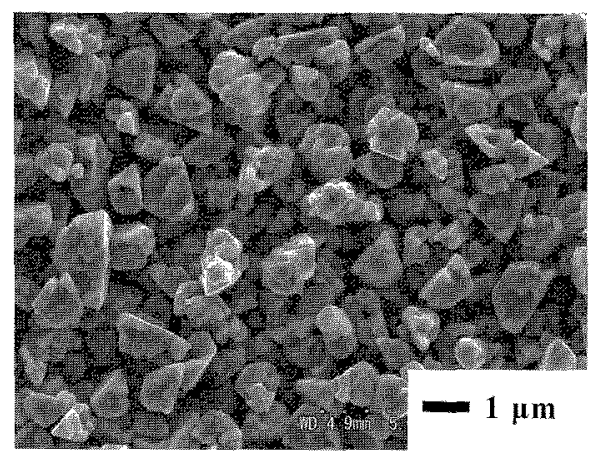

Fig.6 SEM image of a CuSCN thin film electrodeposited at $+0.2 \mathrm{~V}$

\section{CONCLUSION}

It has been elucidated that cathodic electrodeposition of CuSCN from aqueous mixed solution containing $\mathrm{Cu}^{2+}$ and $\mathrm{SCN}^{-}$ions is typically limited by transport of $\left(\mathrm{Cu}^{2+}\right)\left(\mathrm{SCN}^{-}\right)$complex. The diffusion limited current can now be fully described for given composition and temperature of the bath, taking the frequency factor and activation energy determined in the present study. Since Faradic efficiency of $100 \%$ can be assumed under diffusion limited conditions, it has become possible to predict the rate of CuSCN deposition. However, it has turned out that surface reactions related to the nucleation and crystal growth play significant roles in the evolution of the film morphology. In order to achieve full control of the film structure especially in view of effective filling of nanopores for device fabrication such as solar cells employing electrodeposited CuSCN, it is necessary to understand the surface reactions and factors to control them. Parameters such as concentration of the complex, temperature and overpotential are expected to be useful means to control the surface reactions. Further studies are on their way with such a strategy.

\section{ACKNOWLEGIMENT}

This work was supported by Industrial Technology Research Grant Program (06A22002d) from New Energy and Industrial Technology Development Organization (NEDO) of Japan.

\section{REFERENCES}

[1] B. O'Regan, M. Grätzel, Nature., 353, 737 (1991).

[2] T. Yoshida, M. Tochimoto, D. Schlettwein, D Wöhrle, T. Sugiura, H. Minoura, Chem. Mater, 11, 2657 (1999).

[3] T. Yoshida, K. Terada, D. Schlettwein, T. Oekermann, T. Sugiura, H. Minoura, Adv. Mater., 12, 1214 (2000).

[4] T. Yoshida, T. Oekermann, K. Okabe, D. Schlettwein, K. Funabiki, H. Minoura, Electrochem., 70, 470 (2002)

[5] T. Yoshida, T. Pauporté, D. Lincot, T. Oekermann, H. Minoura, J. Electrochem. Soc., 150, 9 (2003).

[6] K. Tennakone, G. R. R. A. Kumara, A. R. Kumarasinghe, K. G. U. Wijayantha, P. M. Sirimanne, Semicond. Sci. Technol., 10, 1689 (1995).

[7] K. Tennakone, G. R. R. A. Kumara, K. G. U. Wijayantha, Semicond. Sci. Technol., 11, 1737 (1996).

[8] K. Tennakone, G. R. R. A. Kumara, I. R. M. Kottegoda, K. G. U. Wijayantha, Semicond. Sci. Technol., 12, 128 (1997).

[9] H. Kawazoe, M. Yasukawa, H. Hyodo, M. Kurita, H. Yanagi, H. Hosono, Nature., 389, 939 (1997).

[10] J. He, H. Lindström, A. Hagfeldt, S.-E. Lindquist, $J$. Phys. Chem., B., 103, 8940 (1999).

[11] B. O'Regan, D. T. Schwartz, Chem. Mater., 7, 1349 (1995).

[12] G. R. R. A. Kumara, A. Konno, G. K. R. Senadeera, P. V. V. Jayaweera, D. B. R. A. De Silva, K. Tennakone, Sol. Energ. Mater. Sol. Cells., 69, 195 (2001).

[13] B. R. Sankapal, E. Goncalves, A. Ennaoui, M. Ch. Lux-Steiner, Thin Solid Films., 451, 128 (2004).

[14] K. Tennakone, A. R. Kumarasinghe, P. M. Sirimanne, G. R. R. A. Kumara, Thin Solid Films., 261, 307 (1995).

[15] W. Wu, Z. Jin, Z. Hua, Y. Fu, J. Qiu, Electrochim. Acta, 50, 2343 (2005)

[16] B. O'Regan, D. T. Schwart, S. M. Zakeeruddin, M. Grätzel, Adv. Mater., 12, 1263 (2000).

[17] M. Shin, Y. Umebayashi, R. Kanzaki, S. Ishiguro, $J$. Colloid. Interface Sci, 225, 112 (2000).

[18] E. B. Sandell, "Colorimetric Determination of Traces of Metals", 3rd Ed. Interscience Publishers, New York (1959) p443.

(Recieved January 15, 2008 ; Accepted March 24, 2008) 